\title{
EL PROBLEMA DE LA TRANSICIÓN JURÍDICA DESDE LA CAÍDA DE ROMA A LA EDAD MEDIA:
}

MARGARITA FUENTESECA DEGENEFFE Prof. Titular de Derecho Romano Universidad de Vigo

SUMARIO: 1.- Un planteamiento previo y dilemático: ¿cataclismo de la romanidad o continuidad romano-germánica?

2.- La nueva sociedad eclesiástica y feudal europea

3.- El Derecho en la transición a la Edad Media

4.- El problema del Estado feudal germánico

\section{1.- UN PLANTEAMIENTO PREVIO Y DILEMÁTICO: ¿CATACLISMO DE LA ROMANIDAD O CONTINUIDAD ROMANO-GERMÁNICA?}

Durante mucho tiempo se mantuvo la idea del hundimiento catastrófico de la cultura romana como consecuencia de las llamadas invasiones bárbaras. En obras de figuras ilustres de Roma, como la «Guerra de las Galias» de César o la titulada «Germania» de Tácito, los pueblos germanos venían calificados como barbarí, bárbaros, y a ellos la historiografía moderna atribuyó la destrucción de la cultura romana 1.

Esta concepción catastrofista de las invasiones germánicas se manifestó ya en los humanistas del Renacimiento, que al descubrir el arte y los escritos y toda la grandeza de la Roma antigua, afirmaron la superioridad de la cultura romana en compa-

1 Vid. DOPSCH, A., Wirtschaftfliche und soziale Grundlagen der europäischen Kulturentwicklung aus der Zeit Caesar bis auf Karl den Großen $2^{\text {a }}$ ed. Wien, Seidel und Sohn, 2 vols. 1923 y 1924. (Trad. esp. Fundamentos económicos y sociales de la cultura europea, Fondo de cultura, Méjico, 1951; DAWSON, The making of Europe. An introduction to the history of European unity, London, 1935; PIRENNE, H., Mahomet et Charlemagne Brüssel, 1936. 
ración con el bajo nivel cultural de los invasores germanos que ocuparon los territorios del imperium romanum ${ }^{2}$.

Y esta visión de los humanistas fue reavivada en el siglo XVIII por la Ilustración francesa. Así Montesquieu demostró su interés por Roma en su obra «Consideraciones sobre las causas de la grandeza de los romanos y de su decadencia» (1734), y Voltaire en la «Filosofía de la Historia» muestra su admiración por los romanos y por los griegos. La cultura greco-romana fue, según estos autores y varios más, arruinada por los bárbaros. Hay que advertir que esta teoría del cataclismo de las invasiones bárbaras fue formulada en los países latinos, Italia, Francia y España donde perduró. En Francia, el historiador Guizot aceptó las ideas de Montesquieu y de Voltaire ${ }^{3}$.

En Alemania se desarrolló, en cambio, una teoría contraria, como resultado de investigaciones sobre la economía y la sociedad primitiva de los germanos, según las cuales la libertad y la igualdad practicada en la vida de estos pueblos daría lugar a un gobierno propio y característico de las comunidades germánicas. Estas ideas elaboradas en una larga cadena de estudios, sirvieron para mejorar la tesis de la incultura de los germanos y llegaron a construir una concepción de la sociedad y del Estado germánicos fundada en la teoría sociológico-colectivista, que considera que la propiedad colectiva de la tierra se halla en las primeras fases de la historia, junto con la libertad y la igualdad de los colonizadores, mucho antes que la propiedad privada 4.

2 Vid. JOACHIMSEN, Geschichtsauffassung und Geschichtsaufschreibung in Deutschland unter dem Einflu $\beta$ des Humanismus, en Beiträge zur Kulturgeschichte des Mittelalters und der Renaissance a cargo de Walter Goetz. Sobre la atribución de la destrucción violenta del mundo romano a los germanos en general, o a los «godos» en opinión de los humanistas, cfr. op. cit. vol. VI, pp. 76 ss.

3 Montesquieu y Voltaire se mantienen en el punto de vista germanófobo de los humanistas (Vid. DOPSCH, op. cit. trad. Fundamentos... cit. p. 21). Vid. MONTESQUIEU, Considerations sur le causes de la grandeur des Romains et leur décadence (1734); Id. L'Esprit des lois (1748); GUIZOT se situó en la línea de germanofobia al realizar una nueva edición de la obra del abate MABLx, Essays sur l'histoire de France, punto de referencia preferido de Montesquieu. Sobre éste y Voltaire vid. MEINECKE, F., El historicismo y su génesis, Fondo de cultura, México, pp. 71-157. ARON, RAYMOND, califica a Montesquieu como sociólogo, en Les Etapes de la pensé sociologique (Cfr. trad. esp. ed. Siglo XX, Buenos Aires, 1970, pp. 36-89); ALTHUSER, L., Montesquieu: la política y la historia Barcelona, Ariel, 1974 , p. 34

(... antes de referirse a la práctica de las ciencias experimentales la ley pertenecía al mundo de la religión, de la moral y de la política. Su sentido estaba impregnado de exigencias emanadas de las relaciones humanas... La ley era como un mandamiento).

4 Frente a la teoría del cataclismo, básicamente de origen latino, se forjó en Alemania otra concepción totalmente opuesta, por iniciativa de un funcionario de la Administración pública, que se 
Los estudios de las agrupaciones sociales en la historia primitiva de los diversos pueblos descubrieron procesos paralelos según estudiosos como Sumner Maine ${ }^{5}, y$, sobre todo, el americano Morgan 6 , el cual considera que todos los pueblos han recorrido caminos análogos en su evolución. Esta metodología sociológica contribuyó a relegar la teoría catastrofista de la destrucción de la cultura romana, que culpaba de la catástrofe a las invasiones de los germanos 7 . La idea de una ruptura cultural fue superada por la tesis de la continuidad entre los últimos tiempos del imperio romano y los primeros siglos medievales. Puede admitirse hoy que la transición no se presenta como una dramática disyuntiva entre la ruptura y la continuidad sino como una compenetración entre la romanidad y el germanismo, que fue transformando el impe-

convirtió en el fundador de la historia de la economía alemana: JUSTUS MÖSER, de Osnabrück. Möser partió de la idea de investigar en Westfalia, su tierra de origen, las instituciones agrarias primitivas, que él consideraba como las más primitivas, y rechazando las informaciones de César, que se referían a un estado de guerra. La propiedad individual de Westfalia (Einzelhöfe) constituiría la forma primitiva de colonización. Las tesis de Möser fueron adoptadas por los investigadores del Derecho alemán. Así HÜLLMANN, (K.D.) establece la teoría del régimen señorial, de agricultores sedentarios, con grandes haciendas en donde el dueño es legislador y juez de sus vasallos que le prestan servicios de carácter económico y militar Geschichte des Ursprungs der Stánde in Deutschl vol. 1. pp. 13 ss.). También la teoría de la «marca» de Möser fue adoptada por EICHHORN, en su obra Deutsche Staats- und Rechtsgechichte (1808). Esta investigación germánica respecto al suelo e instituciones relacionadas con éste como las marcas, en definitiva, la historia agraria, hizo que las instituciones públicas y el Estado, aparecieran como emanación del régimen del suelo.

5 Ancient Law (1861) es una de las primeras obras de SUNMER MAINE, que en 1871 publicó Village Communities in the East and West. La difusión de estas ideas en Francia fue realizada por LAVELEYE en Revue des deux Mondes (1872), vol. I. pp. 100-135. y vol. II pp. 505 ss bajo el título Les formes primitives de la propieté. En 1875 publicó Sumner Maine sus Lectures on the early history of Institutions, en la que vuelve al tema de la comunidad de la aldea (village co utilizando la obra de MAURER, publicada en 1854: Einleitung zur Geschichte der Markt-Hof-Dorf-und Stadtverfassung und der öffentfichen Gewalt.

6 MORGAN, en su obra The ancient society (1877) intenta una explicación sociológica válida para toda la historia de la humanidad porque en todas las partes del mundo se habría desarrollado un proceso evolutivo análogo. Las investigaciones de Morgan sobre la organización familiar primitiva y el matriarcado fueron utilizadas por ENGELS, F., Der Ursprung der Familie der Privateigentums und des Staates. Im Anschlu $\beta$ an Lewis H. Morgan's Forschungen, Zürich 1884.

7 El resultado más influyente de toda esta investigación fue logrado por GIERKE, 0., con su obra Das deutsche Genossenschaftsrecht, cuyo vol I apareció en 1868, cuando estaba en auge el movimiento asociativo en la vida germánica, que para Gierke es la base de toda la estructura social y política. Gierke introduce en su teoría societaria la distinción entre las asociaciones de tipo económico y las de tipo político. 
yeron un tejido eclesiástico con funciones religiosas y administrativas que se extendió por el solar del antiguo imperium. A pesar de la uniformidad de esta red institucional eclesiástica, la Iglesia, en cada reino, desarrolló algunas peculiaridades propias. Así, la Iglesia franca, con mayor supeditación de los obispos al rey y mayor independencia respecto al Papado, se convirtió en un foco de poder y cultura cristiana que impulsó el imperio de Carlomagno ${ }^{13}$.

Por otra parte, como ya hemos dicho, el poder eclesiástico tuvo un aliado en el feudalismo, gracias al cual se instauró la organización militar en los reinos germánicos debido a los vínculos de vasallaje y a la peculiar economía agraria heredada del Bajo Imperio romano, del que subsistían figuras como el precarium y el patrocinium de los grandes señores territoriales, que incluso fundaron monasterios propios. $\mathrm{La}$ antigua clientela romana aparece todavía subsistente en el feudo (vassos). Precisamente la naturaleza del feudo se ha considerado como mezcla de factores romanos, germánicos y eclesiásticos.

Esta sociedad medieval europea que hemos descrito significa un alejamiento enorme de la sociedad greco-romana antigua. La idea de la ciudad política grecoromana desapareció bajo el sistema feudal, si bien reaparecerá en los últimos siglos medievales en las ciudades italianas.

\section{3.- EL DERECHO EN LA TRANSICIÓN A LA EDAD MEDIA}

La tendencia codificadora del Bajo Imperio tuvo una importante manifestación en el Codex Theodosianus, compilado por obra del emperador Teodosio II, que regía la parte oriental del imperium, promulgado en Oriente el año 438 y enviado a Occidente, entró en vigor en ambas partes del Imperio el 1 de enero del 439 d.C. 14

Recopila las leges generales a partir de Constantino ordenadas en libros y títulos, como se había hecho en dos compilaciones privadas de constitutiones imperiales que se denominan Codex Gregorianus y Codex Hermogenianus. Habrá de transcurrir casi un siglo hasta que Justiniano, emperador asentado en la pars orientis del imperium (Constantinopla) llevase a cabo entre los años 530-534 la gran Compilación de Derecho romano, compuesta de cuatro partes (Institutiones, Digestum, Codex y Novellae leges) que en la Edad Media sería denominado Corpus Iuris Civilis. Justiniano pretendía, desde Oriente, recuperar los territorios occidentales del impe-

13 Vid. sobre el Papado ULLMANN, W., Principios de gobierno y política en la Edad Media Rev. Occidental, Madrid, 1971, pp. 33-91; vid. asimismo ULLMANN, W., Historia del pensamiento politico en la Edad Media, Ariel, Barcelona, 1983.

14 FUENTESECA, P., Historia del Derecho romano, Madrid, 1987, p. 280-6. (Cfr. Derecho postclásico; Iura et leges; Las compilaciones occidentales; Codex Theodosianus). 
rium cuando éste había caído ya en poder de los bárbaros al ser depuesto el último imperator, Rómulo Augustulo por Odoacro, caudillo germánico, que envió al emperador de Oriente las insignias simbólicas del imperium, en el año 476. Por el extremo occidental del imperium habían iniciado la penetración las masas de los suevos, vándalos y alanos que cruzaron el Rhin en el año 406, y tres años después entraron en España. Los visigodos, que al mando de Alarico habían llegado a Roma en el 410, lograron un pacto con los romanos y se establecieron al Sur de la Galia (418) desde donde pasaron a España. En el siglo $\mathrm{V}$ se produce el avance de los germanos sobre el imperium de Roma ${ }^{15}$.

Este gran movimiento de ocupación del imperium por las estirpes godas es la culminación de muchos contactos durante largos años en las fronteras del Rhin y del Danubio en las que recibieron el influjo de la cultura romana y en especial, del cristianismo. El asentamiento se realizó en virtud de acuerdos de hospitalidad al servicio de Roma y recibiendo una cuarta parte de las tierras. No podemos detenernos en este fenómeno de incorporación pacífica y sin carácter de cataclismo, porque debemos ahora referirnos a los aspectos jurídicos de la invasión goda.

Nos encontramos con una legislación de estos nuevos pueblos, situados dentro de las fronteras del antiguo imperium, que, formalmente, parece responder al estilo de la actividad codificadora del Bajo Imperio romano. En efecto, la primera edición del Codex Euricianus (=Código de Eurico), fue promulgada en el año 475, por el rey visigodo Eurico, que recopila fuentes jurídicas romanas elementales.

Hace unos años se realizó en España, por obra del ilustre romanista Alvaro D'Ors una edición crítica del Codex Eurici, utilizando el manuscrito que se conserva en París. Este Código de Eurico, aunque se conserva de modo incompleto, presenta una clara influencia del Derecho romano, de tal modo que ha sido calificado por el prof. D'Ors como una fuente de Derecho romano vulgar y no del derecho visigodo, hasta el punto de suponer que más que un código visigodo podría tratarse de un edictum romano para suplir la ausencia del Prefecto de Arlés provocada por la deposición del último emperador romano en 47616 .

El Código de Eurico es una pieza clave en la Historia del Derecho español cuyas raíces se discuten entre romanistas y germanistas. Por ello volveremos sobre este punto.

Otro documento legislativo importante de los godos es el denominado Edictum Theodorici, promulgado en Italia hacia el año 500 por el rey de los ostrogodos Teodorico el Grande, que desempeñaba el cargo de Prefecto de Italia en nombre de Zenón, emperador romano de Oriente. Desde el punto de vista formal presenta ana-

15 Vid, FUENTESECA, P., op. cit., pp. 287-303.

16 Vid. d'ORS, A., Estudios visigóticos II, (El Código de Eurico), Cuadernos del Instituo Jurídico Español, n 12, Roma (1960) (=Consejo de Investigaciones, Madrid 1960). 
logías con el Código de Eurico antes mencionado. Las fuentes de este Edictum Theodorici son romanas, del Bajo Imperio, concretamente el Código Teodosiano, Sentencias de Paulo e Instituciones de Gayo, así como los Códigos privados Gregoriano y Hermogeniano. Las analogías de este Edictum de Teodorico con el Código de Eurico son tan notorias que se ha llegado a pensar que su autor haya sido el rey visigodo Teodorico II y no Teodorico el Grande, el rey de los ostrogodos (los godos del Este), establecido en Italia, pero vinculado a la Corte bizantina del emperador de Oriente. El Edictum de Teodorico el Grande, al que venimos refiriéndonos, parece responder a un propósito de comportarse como un magistrado romano, ya que éstos promulgan edictos y no leges, función ésta que correspondería al imperator de Oriente en este caso. Este guerrero germánico que fue Teodorico el Grande, había sido adoptado por el emperador de Oriente y ostentó los títulos romanos de consul, patricius y magister militum. Se trata del ejemplo más claro del modo de inserción de los godos en los mecanismos del poder del imperium, mediante asunción de funciones, en especial militares, al servicio de los emperadores.

Se reconoce por los autores alemanes como Mitteis (H.), que los ostrogodas de Teodorico fueron los más romanizados, si bien los autores italianos lo habían ya admitido también. Teodorico el Grande recuperó hacia el Norte (Provenza) los antiguos dominios imperiales perdidos. Estos éxitos de Teodorico sirvieron para admitir una hegemonía de éste sobre los demás reinos bárbaros (visigodos, burgundios, francos) y con ello la hipótesis de un imperium germánico teodoriciano, elaborada especialmente hace años por historiadores alemanes nacional-socialistas. La hipótesis de un gran imperio germánico con anterioridad a Carlomagno que los mencionados historiadores intentaron construir, ha sido considerado como un exceso de germanismo (Germanentum) propio de la época nazi. Incluso la construcción imperial de Carlomagno, el imperio carolingio, tiene más características romanas del imperium christianum del Bajo Imperio, que germánicas. De ahí la denominación de Sacro romano imperio germánico. El germano Teodorico estuvo al servicio del emperador romano de Oriente y su edicto se basa en la legislación bajo-imperial y declara en el proemio de su edicto la reverencia a las leyes romanas cuyas normas deberán seguir los bárbaros y los romanos ${ }^{17}$.

Otra compilación goda fue la Lex Romana Burgundionum realizada por orden del rey de los burgundios Gondebaudo hacia el año 500 y tiene las mismas fuentes romanas que el Edictum Theodorici. Suele admitirse que antes de esta ley romana había

17 Sobre esta hipótesis de un presunto imperium germánico, anterior a Carlomagno, surgido de la conciencia de unidad de los germanos ya en tiempos de las invasiones germánicas, hay una literatura de inspiración nacional-socialista, que señala a Teodorico el Grande como forjador de ese proto-imperio germánico; vid. MTTEIS, H. Staat des Mittelalters (1940) 149 ss. En especial, con bibliografía, KOSCHAKER, P. op. cit. pp. 12 ss y pp. 316 ss. 
sido realizada una compilación, en la que se contenían constituciones de los reyes borgoñones (Llamada Lex Gombetta) del año 502. De ello se deriva la opinión que atribuye al rey Gondebaudo dos legislaciones, una primera para los borgoñones y otra posterior para los romanos, si bien cabe pensar que esta segunda ley podría ser una síntesis moderada de la anterior. Dado que los borgoñones fueron considerados a principios del siglo VI como foederati y muy vinculados al emperador de Constantinopla, los reyes borgoñones se hallaban rodeados de altos dignatarios romanos que desempeñaban cargos administrativos, y también de obispos católicos. Parece haber existido una vinculación análoga a la de Federico el Grande con el imperium y ello hace difícil admitir, como se ha hecho, que el rey Gondebaudo haya establecido dos leyes separadas, una romana y otra de los borgoñones. La dualidad de legislación para bárbaros y romanos es una idea muy arraigada en los estudiosos porque se la considera basada en un principio antiguo de la personalidad de la ley, que, como veremos, forma parte de la polémica iniciada en el siglo pasado entre romanismo y germanismo.

Por último hay que mencionar la Lex Romana Wisigothorum, también llamada Breviario de Alarico, un código promulgado en el año 506 por el rey visigodo Alarico II en Toulouse (Tolosa) en el Sur de Francia antes de la entrada de los visigodos en España. Se trata de la compilación más amplia e importante de todas las mencionadas antes. Fuentes de esta colección son el Codex Teodosianus y las nuevas leyes de Teodosio (Novellae leges) y otras post-theodosianas. Pero la mayor novedad en materia de fuentes es la incorporación de fragmentos de obras de juristas romanos, como las Sentencias de Paulo (Pauli Sententiae), una obra breve conocida como el epítome de Gayo (Epitome Gai), un fragmento de Papiniano y fragmentos de los códigos Gregoriano y Hermoganiano. Esta incorporación en una compilación visigoda realizada en Occidente de obras de los juristas romanos de época clásica ya muy manipuladas en época postclásica romana, prueban la pervivencia de textos jurisprudenciales romanos en el Occidente en donde debieron subsistir dichos textos jurídicos romanos utilizados en la vida judicial y en algunas escuelas jurídicas occidentales.

Esta Lex Romana Wisigothorum, también conocida como Breviarium Alaricianum, presenta enigmas muy sugerentes que encierran muchas claves de la vida jurídica en la transición a la Edad Media. En primer lugar hay que observar que se trata de una lex promulgada por un rey godo, Alarico II, pero cuyo contenido jurídico es romano. Parece más bien que se trata del Derecho romano que regirá para los visigodos de Alarico II, en disposición ya de entrar en España. La notable amplitud de esta compilación hace pensar en una aceptación de la normativa jurídica válida para la práctica jurídica, puesto que los preceptos jurídicos recogidos en el Breviario se acompañan de un comentario o interpretatio claramente dirigido a la aplicación práctica en los tribunales. Esta interpretatio ha sido defendida por el más entusiasta defensor del Derecho vulgar de Occidente, Ernst Levy, para probar la existencia de un Derecho romano vulgar en la época de la legislación visigoda. Levy había detectado previamente las sucesivas manipulaciones sufridas por las Sentencias de Paulo 
a lo largo de la época postclásica, como ya hemos dicho. La interpretatio con que aparecen acompañadas las mencionadas Sentencias en el Breviarium Alaricianum responde a una vulgarización de las ideas jurídicas romanas. Y en la misma línea de Derecho vulgar romano ha sido colocado el Código de Eurico, que, como ya se ha dicho, es el más antiguo código visigodo en España (año 475) como resultado de la edición crítica del manuscrito de París por el prof. A. D'Ors. Por tanto, la más importante legislación visigoda, el Breviarium Alaricianum y el Código de Eurico no pueden encuadrarse en el Derecho germánico. Más adelante volveremos a referimos a esta polémica.

Otra clave interesante del Breviarium es que su contenido no encierra solamente constituciones que, en lenguaje imperial romano se denominaban leges, sino también lo que los romanos calificaban de ius, es decir, escritos jurisprudenciales, como hemos visto en este caso, de Paulo, Gayo y Papiniano. Esta conjunción de leges y ius en el Breviarium hace pensar en los designios de la compilación de Justiniano, que proyectó la compilación de ius y lex que sería realizada en Constantinopla unos treinta años más tarde (desde el 530 al 534). Tanto las leges como el ius adquieren así la misma categoría de normas legítimas en virtud de la sanción imperial, tanto en el Breviarium de Alarico como igualmente en el Código (leges) y en el Digesto (ius) en virtud de la sanción de Justiniano, que envía su compilación a Occidente, al Papa Vigilius, para que se admitiese su vigencia en la pars occidentis, y en este hecho encontramos una clave muy importante para la interpretación de esta época histórica, que es el siglo VI, año siguiente a las invasiones bárbaras (siglo V).

Nos referimos al paralelismo entre las dos compilaciones, el Breviarium Alaricianum y la Compilación de Justiniano, bajo otros aspectos, además de recopilar a la vez leges y iura. El Breviarium constituyó la mayor compilación de Derecho romano del Occidente y constituye un producto de la cultura jurídica occidental, de más bajo nivel que la oriental. Es discutible hasta qué punto se llegó a utilizar en Occidente la Compilación enviada por Justiniano. Entonces estaba ya separada la actividad legislativa en cada una de las partes del imperium desde que Teodosio, en el año 429, ordenó que cada emperador fuese libre de acoger o no las leges generales emanadas del otro. Por eso Justiniano envía desde Constantinopla su gran Compilación a Roma con una comunicación oficial (pragmatica sanctio) al Papa Vigilius para que se dignase aceptarla. Sin embargo la Compilación de Justiniano era una obra demasiado amplia que comprendía cuatro partes (Institutiones, una obra elemental del ius civile para la enseñanza; Digestum, un enorme volumen de opiniones de juristas; Codex, una larga serie de leges de los emperadores; Novellae leges, nuevas leyes de los emperadores, posteriores al mencionado Codex). Los comisionados de Justiniano que hicieron esta Compilación pudieron utilizar los libros en que enseñaban derecho los profesores de las Universidades de Berito y Constantinopla y, a pesar de ello, su labor duró cuatro años (530-534).

Como ya hemos dicho, el saber jurídico y la cultura, en general, tenía más alto nivel en el Oriente del Imperio que en Occidente. Por eso resulta difícil admitir que 
la Compilación de Justiniano, haya sido utilizada ni siquiera en Italia y mucho menos en Francia o España. Esta compilación se prestaba únicamente para un estudio más profundo del Derecho romano, como así habría de ocurrir a partir del siglo XI, cuando comenzaron a crearse las universidades y en Bolonia se inició la enseñanza del Derecho romano. Entonces se producirá la primera recepción del Derecho romano como un verdadero saber jurídico, que estudiaron centenares de alumnos de toda Europa, que acudían a Bolonia. Desde entonces empezó a llamarse Derecho común al Derecho romano, frente a los derechos locales y singulares de las pequeñas entidades: ciudades, señoríos feudales y principados, que constituían un complejo mosaico de jurisdicciones particulares, sobre todo en Alemania e Italia.

Ahora interesa únicamente destacar que median varios siglos desde la caída de Roma hasta el mencionado Renacimiento jurídico, que se iniciará en el siglo XI en Bolonia con ayuda de los emperadores del sacro-romano imperio germánico, instaurado por Carlomagno, con apoyo de la Iglesia franca, la más culta y la más unida desde entonces. Pero esto merece tratamiento aparte en el cual no vamos a entrar ahora.

Para cerrar este análisis de las monarquías godas y el derecho germánico, es necesaria una alusión a la polémica entre romanismo y germanismo, que, surgida en Alemania, tuvo en España un especial relieve. Desde que Savigny revitalizó la historia jurídica y se preocupó de la historia del Derecho romano en la Edad Media, comenzaron en Alemania los estudios acerca del derecho germánico. En España, el conocido historiador del Derecho, Hinojosa, se convirtió en defensor de la influencia germánica en la historia del derecho medieval español, influencia que creyó encontrar en algunos fueros. Los municipios romanos, de los que en España tenemos la mejor información gracias al hallazgo de varias leyes municipales en bronce, según la teoría germanística, habrían desaparecido con la ruina de muchas ciudades ${ }^{18}$.

Asimismo, en la esfera de la historia literaria, los cantares de gesta, según Menéndez Pidal, tendrían origen godo. A esto se unió la idea de pujanza y unidad del Estado visigodo en donde la Iglesia desempeñó una función directiva, hasta el punto de que los concilios toledanos, integrados por obispos, dictaban normas que los reyes sancionaban. La nobleza goda constituía la aristocracia que detentaba la función militar. Después de la caída de España en poder de los árabes, los designios del momento inicial de la Reconquista eran la recuperación del orden gótico de Toledo ${ }^{19}$. Toda una concepción de la reintegración de España se hallaba basada en el neogoticismo, según

18 Vid. FUENTESECA, M., La polémica entre el romanismo y el germanismo en el derecho visigótico y la posesión de bienes muebles en el derecho español (Código Civil, art. 461 Comunicación al $51^{\circ}$ Congreso SIHDA (Crotone-Messina, 16-20 sept. 1997, en cuyas actas aparecerá publicada.

19 Sobre la recuperación del orden gótico como designio toledano y el influjo de la idea imperial carolingia en los primeros siglos de la Reconquista, vid, FUENTESECA, P., La recepción de la idea 
la visión que impuso Menéndez Pidal de la historia de España y que había sido antes impulsada en el terreno de las instituciones jurídicas por Sánchez Albornoz, defensor también del derecho godo. Así del campo jurídico pasó la polémica al ámbito de la historia política de España.

Ciñéndonos a la historia jurídica, la oposición a Hinojosa se inició por GarciaGallo cuando se opuso a la idea, tradicionalmente admitida, de la personalidad del derecho visigodo. Este tradicional principio consistía en suponer que en el reino visigodo existían dos distintas legislaciones: una para los hispano-romanos y otra para los visigodos. Según este principio, el Código de Eurico se habría establecido para los visigodos, mientras el Breviario de Alarico sería destinado a los hispano-romanos. Y el Codex Revisus de Leovigildo, por constituir una simple revisión del de Eurico, correspondería a la población visigoda. A esta teoría de la personalidad, según la cual existirían leyes distintas para godos y romanos, se añade una contraposición entre el derecho visigodo legislado, que es el contenido en la legislación de época goda, que hemos mencionado, y un presunto derecho consuetudinario germánico-visigótico, que habría pervivido según los germanistas por debajo del derecho visigodo legal, para resurgir manifestándose en los documentos de los siglos alto medievales. A la complejidad de la teoría de la personalidad se le añadía la difícil distinción entre un derecho legislado visigótico más romanizado y otro derecho consuetudinario germánico subsistente por debajo hasta renacer, como ya hemos dicho, en documentos alto-medievales. A la teoría de la personalidad se opuso también el ilustre romanista A. D'Ors, defendiendo, como García-Gallo, la teoría de la territorialidad, aunque se aparta en un punto de ésta, admitiendo que el Breviario no derogó al Código de Eurico sino que convivió con él. La oposición a la teoría de la personalidad y el reconocimiento del carácter de derecho vulgar del Código de Eurico, hechas por un gran romanista como el prof. A. D'Ors, tiene una garantía de acierto. Ya hemos expuesto el contenido romano esencial del Breviario de Alarico y respecto al Código de Eurico hemos admitido la calificación de derecho vulgar señalada por el prof. A. D'Ors. En la época de promulgación del Codex Euricianus (475) los visigodos eran formalmente súbditos del imperium y no se trataría de un código personal para los visigodos, sino una colección de preceptos de derecho vulgar romano vigentes entre los romanos provinciales.

En nuestra opinión no ha sido quizá enteramente acertado el planteamiento de esta polémica contraponiendo personalidad y territorialidad del derecho. La personalidad del derecho en Roma, como en Grecia, existía en el sentido de que el derecho de la ciudad correspondía únicamente a la persona en cuanto ciudadano. La persona carente de ciudadanía no gozaba del ius civile porque éste era el derecho propio de la ciu-

imperial en la Edad Media española y sus raices romanas en Studi Sassaressi, VIII, Univ. Sassari (Cerdeña), 1980, pp. 63-97 =Estudios prof. J. Iglesias, II, 747 ss, Madrid, 1988. 
dad y del ciudadano. La idea de territorialidad del derecho, en cambio, no aparece hasta que el famoso edicto de Caracalla extendió la ciudadanía a todos los habitantes del imperium salvo los dediticios. Aquí aparece una aplicación, aunque no muy clara, del derecho en función de la territorialidad, pero todavía así se trata de concesión de ciudadanía romana como instrumento o medio de adquisición de derechos. En concreto, la legislación visigoda, otorgada por caudillos militares visigodos asentados en el solar del imperium, otorga leges romanas, que son preceptos romanos, vulgarizados en gran parte, para el grupo de la población al servicio del jefe godo. Así la Lex Romana Wisigothorum sería la lex romana que Alarico II otorga a sus visigodos, igual que los burgundios tienen otra dada por su rey y asimismo cabe admitir que sería esta Lex Romana Burgundionum la lex romana de los borgoñones 20.

Por último, hay que hacer notar, como hipótesis para una más detenida investigación, que las fuentes romanas mencionadas en la Lex Romana Wisigothorum acaso hayan sido recogidas siguiendo el mandato de la famosa «Ley de Citas» de Valentiniano III, del año 426, según la cual las citas de los juristas clásicos deberían limitarse a los cinco autores siguientes: Papiniano, Gayo, Paulo, Ulpiano y Modestino. Esto significa que la opinión de los cinco jurisconsultos quedaba reconocida por el emperador con eficacia normativa igual que las leyes, si nos atenemos a la opinión de Gayo I,7.

Si existiesen divergencias entre las opiniones, se debería seguir la opinión de la mayoría y si existiese un empate entre dos opiniones contrapuestas prevalecerá la opinión de Papiniano. Esta disposición de Valentiniano III, emperador de Occidente, fue recogida en el Codex Theodosianus tres años después (429). Sin duda esta reiteración de la misma norma por Teodosio se debe a que este emperador estableció la separación entre la legislación de las dos partes imperii, salvo que un emperador acogiese como leyes propias las procedentes de otro. Este es el caso de Teodosio acogiendo la «Ley de Citas» de Valentiniano. Y este hecho nos hace suponer que la «Ley de Citas» haya tenido vigencia tanto para la compilación de la Lex Romana Wisigothorum en Occidente, como para la compilación de Justiniano en Oriente, unos treinta años posterior a la primera. Respecto a la Compilación justinianea, ya Albertario ${ }^{21}$ en su día expuso esta hipótesis como explicativa del método y rapidez de la tarea compilatoria de la comisión de Justiniano, que habría utilizado extractos de los juristas de la «Ley de Citas». No ha sido debidamente tenida en cuenta esta hipótesis de Albertario, que recordamos ahora, al observar que probablemente la «Ley de Citas» de Valentiniano en Occidente haya servido de criterio para la compilación de la Lex Romana Wisigothorum porque la presencia de Paulo (Sentencias),

20 La vinculación entre la personalidad (Jurídica) y ciudadanía se mantuvo hasta las codificaciones modernas.

21 Vid. ALBERTARIO, Introduzione storica allo studio del Diritto Romano giustinianeo I (1935). 
de Gayo (Epítome) y de Papiniano hallaría así una explicación uniforme para ambas partes del imperio. Y también justificaría la utilización en Occidente de las Sentencias de Paulo con sucesivas manipulaciones vulgarizadoras y el Epítome de Gayo y hasta la mención de un texto del Corpus Papiniani (CTh. 1,4,3), el jurista cuya auctoritas decidía los empates entre opiniones contradictorias y cuya fama llegó a la Edad Media. En Occidente no se disponía de obras jurídicas romanas como en el Oriente, en donde los profesores de Berito y Constantinopla tenían a su disposición obras de la Jurisprudencia romana clásica para sus tareas de enseñanza, hasta el punto que su labor compilatoria como la de los comisionados de Justiniano, no puede explicarse sin la existencia de grandes resúmenes de obras seleccionadas para la función docente. El Digesto de Justiniano fue la mayor acumulación de pensamiento de los juristas clásicos romanos, que conocemos gracias a que llegó un manuscrito a la Universidad de Bolonia y constituyó la base de la ciencia del Derecho Privado europeo occidental e incluso sirvió de impulso para la configuración del Estado moderno como ente público (res publica). Desde estas dos grandes compilaciones del siglo VI, la occidental, que fue el Breviarium Alaricianum (o Lex Romana Wisigothorum) y la oriental (Corpus Iuris de Justiniano) no se produce ninguna novedad importante en el pensamiento jurídico europeo hasta el siglo XI, época en que comenzaron las enseñanzas del Derecho Romano en Bolonia con base en un manuscrito del Digesto. Pero ya entonces se había producido la restauración del poder imperial romano, mediante la renovatio imperii llevada a cabo por Carlomagno, cuyos sucesores al frente del nuevo imperium romano-germánico, apoyaban el estudio del Derecho romano.

\section{4.- EL PROBLEMA DE ESTADO FEUDAL GERMÁNICO}

Los pueblos godos que se instalaron dentro del ámbito del antiguo imperium romanum adoptaron la forma de monarquías militares. El jefe o caudillo godo asumía la función de rex, de raigambre latina, pero su función más importante era el mando militar, organizan su ejército con ayuda de los vínculos feudales de vasallaje propio de los pueblos germanos. La sociedad feudal de la época facilitó a los godos la instauración de una ordenación militar en tomo a los reyes. Esta estructura feudal del exercitus se delata claramente en las fuentes visigóticas españolas revisadas por Sánchez Albornoz ${ }^{22}$. De ordinario eran llamados a la guerra los especialmente vinculados por vínculo de fidelidad feudal (gardingos, leudes, fideles) más los habitantes de la zona de la que debía partir la expedición militar (publica expeditio), porque pocas veces se utilizaría una movilización total. No podemos detenemos en el sugestivo tema de la organización y reclutamiento del ejército en el reino visigótico espa-

22 Vid. SÁNCHEZ ALBORNOZ, El ejército visigodo: su protofeudalización, en Investigaciones y documentos sobre las instituciones hispanas, Ed. Jurídica de Santiago de Chile 1970, p. 5-56. 
ñol. En el tema del reclutamiento militar y su relación con el patrimonio, es probable una influencia bajo-imperial romana (Codex Teodosianus, 7,13,7). Pero lo que ahora interesa destacar es que el rey era el jefe de una compleja organización militar, establecida sobre los vínculos feudales de la sociedad goda.

Pero, además, la figura del rex fue sacralizada por la Iglesia, fenómeno que se produjo en todos los pueblos germanos del Occidente europeo, incluida Inglaterra. Se practicó una ceremonia de ordenación sagrada de los reyes (ordinatio regis) de la que tenemos en España una valiosa muestra integrada por ritos ultrapirenaicos en el llamado «Ceremonial de Cardeña». Sin duda ha existido un ritual análogo de consagración de los reyes (ordo ad regem benedicendum) que llegó de fuera de España, aunque este ritual, como supone Sánchez Albornoz, habría salido anteriormente de la monarquía visigótica española y retornó a España ${ }^{23}$. Por otra parte, en la Historia Compostellana y en la Chronica Adefonsi Imperatoris aparecen ceremonias de caracteres análogos, pero no iguales, puesto que se refieren a una consagración como imperator. Así el de Alfonso VII en Santiago, cuyo ritual, recogido en la Compostellana parece inspirado en la coronación de Carlomagno como imperator por el Papa ${ }^{24}$.

Estos diversos ritos de la ordenación sagrada de los reyes (ordo ad regem benedicendum) en las monarquías occidentales de la alta Edad Media configuran una realeza teocrática, una figura muy alejada de la concepción del poder político del antiguo imperium romanum, basado en la lex de imperio, legalidad que se mantuvo formalmente vigente a través del Bajo Imperio hasta Justiniano. Sin embargo en Roma el imperium christianum bajo-imperial tendió a presentarse como un poder sacropolítico ${ }^{25}$.

Estas monarquías militares de los reinos bárbaros (reino visigodo, borgoñón, franco, longobardo, anglo-sajón) se asientan, como hemos dicho, sobre el nuevo tipo medieval de sociedad, que fue el feudalismo. Nada tienen que ver estos vínculos de fidelidad que obligan al que recibe un beneficio (p. ej. disfrute de una tierra de un señor medieval) con la vinculación política de los ciudadanos propia de la ciudadanía del Estado antiguo greco-romano. Esta es la dificultad de aplicar la noción

23 Vid. SÁNCHEZ ALBORNOZ, C., La ordinatio principis en la España goda y postvisigoda, Cuadernos de la Historia de España, 35-6 (1962), pp. 5-36.

24 Vid. Historia Compostelana nueva edición de FALQUE, EMMA en Akal, 1994, p. 174.

25 Sobre el poder sacro-político producto de la colaboración entre sacerdotium e imperium, vid. FUENTESECA, P., La recepción de la idea imperial en la Edad Media española y sus raíces romanas op. cit. (Comunicación al Congreso Cultura ibérica e Diritto romano, Univ. Sassari, 1980), en Studi Sassaresi, VII (1980-198 1) = Estudios Homenaje Prof. Juan Iglesias, vol II, Univ. Complutense (Seminario de Derecho romano), Madrid 1988, pp. 747-771. 
greco-romana de Estado en cuanto constituyó una comunidad política de ciudadanos característica de la polis griega y de la res publica romana. La esfera de los derechos privados de los ciudadanos constituye el ius civile, que es el ius privatum, frente a la ordenación pública de la comunidad (ius publicum) ${ }^{26}$.

Sin embargo, ilustres estudiosos alemanes han defendido la existencia de una concepción germánica del Estado, en la Edad Media. Es muy discutible la atribución del calificativo político de Estado a los reinos germanos de comienzos de la Edad Media, que, como hemos expuesto, son monarquías militares y teocráticas, basadas en una sociedad de estructura feudal y eclesiástica. El feudalismo fue también utilizado por la Iglesia para la explotación de sus propiedades agrícolas. Algunos autores han hablado de Estado feudal medieval, pero ello exige que le dediquemos una breve atención especial.

En efecto, visto desde Italia, el régimen feudal implica una crisis de la idea política de Estado. Así Calasso 27, con apoyo en las ideas de Besta, considera que el sistema feudal ataca en la raíz la ratio específica del Estado, que es la soberanía. El feudatario, vasallo del rey, es él también señor de otros vasallos y este sistema fraccionó la organización pública en una cadena de relaciones patrimoniales de naturaleza iusprivatista, Esta contaminación entre Derecho público y Derecho privado, constituye, según Calasso, una característica del Estado feudal. En documentos italianos, cuando el antiguo Regnum Longobardorum había pasado a denominarse Regnum Italiae, el rex aparece al mismo tiempo como señor feudal: in regem et seniorem, Posteriormente, en la época de los emperadores otones, que potenciaron a la Iglesia otorgando concesiones feudales a los obispos y a los abades de los grandes monasterios, se llegó hasta a admitir la figura híbrida del obispo-conde. El obispo recibía del emperador la investidura feudal y el episcopado, independientemente de la electio y la consecratio de los obispos, que correspondía a la Iglesia. De aquí surgió con el tiempo la llamada guerra de las investiduras entre el Emperador y el Papa que se intentó regular en el Concordato de Worms (1122) estableciendo un orden de precedencia, de modo que primero se realizaría la libera y la consecratio canonica del obispo y después la investidura feudal 28.

26 Vid. FUENTESECA, P., El gran dilema histórico del pensamiento jurídico europeo: ¿ley pofitica o ley natural?, Publicaciones Univ. Autónoma, Madrid, 1977.

27 Vid. CALASSO, F., Gli ordinamenti giuridici del rinascimento medievale (ristampa della $2^{\mathrm{a}}$ ed.), Milano, Giuffré (1965), pp. 82 y 84.

28 Sobre el feudalismo en general: BLOCK M., La société feodale 2 vol. París, 1940; MOUSNIER, R., Problémes de stratification sociale, Actas del coloquio internacional (1966). Publicación Facultad de Letras, París-Sorbona, Recherches, t. 43. Sobre señorío en general: BLOCH, M., L'Histoire 
De lo expuesto se deduce que el denominado Estado feudal, de cuño germánico no es solamente producto de la crisis de la idea política greco-romana, sino también la anulación del poder público legítimo, cuya base se asentaba en una ordenación que distingue el ius publicum del ius privatum.

rurale française 2 vols. París, A. Collin, $2^{\mathrm{a}}$ d. , 1961-1964; IMBERT, J., Histoire économique des origines a 1789 Pres. Univ. de France, 1965.; ELLUL, J., Histoire des institutions de I'époque franque á la Revolution, Paris, Pres. Univ. France, 1964; LOT, F., y FAUTIER, R., Histoire des institutions françaises au Moyen Age, vol I (1957), vol II (1958), vol III (1962), en Pres. Univ. France. 